\title{
Safe or unsafe driving maneuvers in road traffic
}

\author{
Stanislav Tokař ${ }^{a}$ \\ a Institute of Forensic Engineering, Brno University of Technology, Purkyňova 118, Brno 61200, Czech Republic
}

\begin{abstract}
This article represents an area closely connected to the analysis of road accidents. When the act of accident is being considered by an expert, it often happens that one participant of the accident causes that the other participant has to change suddenly the speed or direction of his/her drive to prevent possible collision. For a proper consideration of the driving manoeuvres we need to know the limit of a sudden change of speed or a sudden change of direction of drive. The limit of suddenness can be taken as the limit between a safe and already unsafe driving manoeuvre (braking, transverse motion) of the vehicle. The author tried to settle this limit by measurements with respondents who were asked to subjectively classify particular driving manoeuvres. For classification of the sudden change of speed, the intensity of deceleration was altered $\left(3 \mathrm{~m} / \mathrm{s}^{2}\right.$, $5 \mathrm{~m} / \mathrm{s}^{2}, 7 \mathrm{~m} / \mathrm{s}^{2}$, and maximum attainable deceleration $a_{\max } \mathrm{m} / \mathrm{s}^{2}$ ). At classifying a sudden change of
\end{abstract} direction, we changed the trajectory of the vehicle's motion with transverse motion in one curve. As a result in the change of trajectory, the magnitude of side acceleration changed (values of side acceleration $2 \mathrm{~m} / \mathrm{s}^{2}, 3 \mathrm{~m} / \mathrm{s}^{2}, 4 \mathrm{~m} / \mathrm{s}^{2}$ and $6 \mathrm{~m} / \mathrm{s}^{2}$ ). From the results achieved it can be settled that the limit of a sudden change of vehicle's speed went round a half of maximally achievable braking deceleration of personal vehicles, at approximately 3,8 to $4,8 \mathrm{~m} / \mathrm{s}^{2}$. The limit of a sudden change of direction of drive went between 2,7 and 3,5 $\mathrm{m} / \mathrm{s}^{2}$.of vehicles' side acceleration. Achieved knowledge can be used in the sphere of road accident analysis when classifying driving manoeuvres of individual participants of the scene of accident. All measurements were taken with personal vehicles, thus it is possible to pay further attention to setting the limit of a sudden change of speed and direction of drive with utility vehicles, lorries and trucks, respectively.

KEYWORDS: Road accident, driving manoeuvres, sudden change of speed, sudden change of direction.

\section{INTRODUCTION}

The term 'A Sudden Change of Speed or Direction of Drive' falls in the sphere of so called technical legal terms. When analyzing road accidents, experts deal with judging, whether the change of speed or direction was a sudden one, or not. These changes are usually expressed by a medium value of braking deceleration, or side acceleration of a particular vehicle, respectively. In the Road Traffic Law no. $361 / 2000$ Dig. (incl. Its amendments), this term is closely linked with the term Give Way, the definition of which is: "Give Way" means that the driver is obliged not to start driving or any act of driving or not to proceed in them if the driver who has the Way had to change suddenly the direction or the speed of driving". In literature Bradáč (1999), there's further claimed that for sudden braking, the still acceptable braking deceleration of the other vehicle is considered the smallest of the following figures:

- Half of the prescribed deceleration

- Half of adhesively attainable deceleration

- Vehicles with standing persons $2 \mathrm{~m} / \mathrm{s}^{2}$

Rivers (2010) at the beginning of his book describes the duration of the act of accident as a series of events on the accident scene (On-Scene Series of Events). He includes situations which happened or may happen, and these we divide into events before the moment of inception of a critical situation (Perception), to which the driver reacts, and those after the moment of inception. At investigation the traffic accident, particular moments of the act of accident are defined in reverse order, it means from the final position of the vehicles back to the moment of possible inception of the critical situation. There's always given the action point, when the driver by his/her acting tries to prevent the collision itself bv reacting to the incepted situation. At calculating or modelling the variations of evasive action it is necessary to know the limit of a sudden change of 
speed or direction, which may be implemented in the calculation itself. On the base of these results, it is possible to consider the act of accident correctly from the side of particular participants.

For the possibility of a wider comparison with results published in foreign literature it is necessary to understand the term 'non-sudden $\mathrm{x}$ sudden' as a change between the state of safe and unsafe.

The authors Langle and Dantu (2009) focused in their thesis on classification of safe and unsafe driving by means of data recording obtained from 'smart' telephones. First, they focused on examples of safe acceleration and decoration. From the measurements obtained it was obvious that safe deceleration had not exceeded $3 \mathrm{~m} / \mathrm{s}^{2}$. Unsafe deceleration reached the figure of $6 \mathrm{~m} / \mathrm{s}^{2}$. In the second half of their work the authors dealt with a safe and unsafe change of a driving lane when driving a vehicle. It meant then a transverse motion through two curves (as a transverse distance they considered the width of a driving lane approximately $3,7 \mathrm{~m}$ ). For a safe change of driving lanes, the maximum of side acceleration hadn't exceeded the figure of $2 \mathrm{~m} / \mathrm{s}^{2}$. Driving maneuvers with side acceleration of approximately $5 \mathrm{~m} / \mathrm{s}^{2}$ were considered as unsafe.

Park, Lee and Koh (2001) dealt in their research with characteristics of drivers according to their perception of the level of deceleration of the vehicle driving in front of them. They formed the needed scale of perception of the level of deceleration by the method of estimating the size between the perceived and real level of deceleration, expressed by "Stevens Power Law". Particular respondents were shown examples of drive of two vehicles going one after another at the speed of approximately $60 \mathrm{~km} / \mathrm{h}$. The distance between the vehicles was approximately $25 \mathrm{~m}$. The respondents were shown 7 examples, which always varied in the magnitude of deceleration of the first vehicle, which was 1,$64 ; 2,04 ; 2,74 ; 3,18 ; 3,74 ; 4,52$ and $5,4 \mathrm{~m} / \mathrm{s}^{2}$. The second vehicle was driving at constant speed. The results of the study showed that majority of drivers underrated the deceleration level of the first vehicle, especially at higher values of deceleration. If the value of deceleration of the first vehicle increased, the level of perceived deceleration was better with women than men, although the highest perceived deceleration level was better classified by men. The difference in perceived deceleration of the first vehicle between novice and experienced drivers was merely minute.

Mrs. Vogel (2003) in her work compares the two safety indicators "headway" and "time to collision
(TTC)". They are discussed and compared with respect to their usefulness in determining the safety of different traffic situations, like different locations in a junction. It is recommended to use headway for enforcement purposes, because small headways generate potentially dangerous situations. TTC, on the other hand, should be used when a certain traffic environment is to be evaluated in terms of safety, because it indicates the actual occurrences of dangerous situations.

Study from Kusano and Gabler (2011) presents a method for determining the time to collision (TTC) at which a driver of the striking vehicle in a real-world, lead vehicle stopped (LVS) rear-end collision applied the brakes. The method was demonstrated using 47 rear-end cases in which there was driver braking. The average braking deceleration for those cases with sufficient vehicle speed information was found to be 0,52 g's. The average TTC that braking was initiated at was found to vary in the sample population from 1,1 to 1,4 seconds.

Naturalistic driving studies (NDS) provide rich source for driver behavior data. The NDS from Kusano, Chen, Montgomery and Gabler (2015) focused on examining time to collision (TTC). Braking behavior was quantified using industry standard time to collision (TTC). Novice drivers (18-20) had lower TTC than middle (31-50) and mature (51+) drivers. Differences in TTC by age and gender were greater at higher travel speeds (> $64 \mathrm{kph}$ )

In the publication Burg and Moser (2009) they declare the dependence of the vehicle's side acceleration on the driving speed at various dynamics of motion. From the results, there is an obvious range of values of vehicle's side acceleration, divided into five defined states (moves) of the vehicle. At normal driving, the used side acceleration ranged from 2 to $3,1 \mathrm{~m} / \mathrm{s}^{2}$, at fast driving the range was approximately 3,1 to $4,4 \mathrm{~m} / \mathrm{s}^{2}$, at sports driving it ranged from approximately 4,0 to $5,7 \mathrm{~m} / \mathrm{s}^{2}$, and at vigorous driving, it ranged from approximately 5,0 to $5,7 \mathrm{~m} / \mathrm{s}^{2}$. With figures ranging from 5,8 to $6,4 \mathrm{~m} / \mathrm{s}^{2}$ it represented a critical driving situation.

Author Kledus (2003) dealt with measuring driving manoeuvres of vehicles, when one of the typical manoeuvres - avoidance manoeuvre, or obstacle avoidance manoeuvre - was simulated. One of the ways of judging was a subjective classification of the manoeuvre's dynamics (by the driver and an observer). From the manoeuvres classified it came out that at continuous manoeuvres with a dynamic 
impression for the passengers, they reached the values of side acceleration 2,5 and $3,8 \mathrm{~m} / \mathrm{s}^{2}$, for dynamic (sports) drive, the values of side acceleration were 5,2 to $6,4 \mathrm{~m} / \mathrm{s}^{2}$, and as a powerful dynamic drive on the limit of safety, they classified manoeuvres reaching side acceleration 7,2 to $7,4 \mathrm{~m} / \mathrm{s}^{2}$. When analysing the driving manoeuvres, there was an obvious direct link between the level of subjective assessment of dynamics of the driving manoeuvre of the vehicle and its average side acceleration value. The work also proved good utility of so called Kovařík's formula.

This thesis was followed by Bradáč jr. (2005), where they assessed driving tests focused on the manoeuvre of transverse motion, or change of driving lanes, respectively. The results of the thesis showed that in common traffic, when the driver doesn't have to divert threatening risk, we use values of side acceleration usually up to $2 \mathrm{~m} / \mathrm{s}^{2}$. On the polygon, common drivers reached values of approximately $4 \mathrm{~m} / \mathrm{s}^{2}$. The maximum values of side acceleration measured reached up to $8 \mathrm{~m} / \mathrm{s}^{2}$, but these were already critical driving manoeuvres beyond limits of safe drive.

A similar research as by the author of this article was conducted by Lukášik (2010), who tried to experiment on setting the limits of a sudden change of speed. The aim of his experiment was to find out the values of the vehicle's deceleration in the course of braking, when participants of road traffic begin to feel subjectively the rise of danger, or they consider this deceleration a sudden change of speed, respectively. During the particular measurements, the respondents were seated in the vehicle as passengers. Their task during each conducted measurement was to settle the level of danger they felt at the vehicle's braking. Four levels of assessment had been chosen (safe, little unsafe, unsafe, very unsafe). Each respondent experienced repeated maneuvers with levels of braking deceleration of $3 \mathrm{~m} / \mathrm{s}^{2}, 4 \mathrm{~m} / \mathrm{s}^{2}$ and $5 \mathrm{~m} / \mathrm{s}^{2}$. For final settling the criterion value between gradual and sudden change of speed of the vehicle, they used the interval (approximately) ranging from 3,7 to $4,0 \mathrm{~m} / \mathrm{s}^{2}$.

Table 1. The research results Lukášik, 2010.

\begin{tabular}{ll}
\hline $\begin{array}{l}\text { Degrees of test drives } \\
\text { assessment }\end{array}$ & $\begin{array}{l}\text { Average value of } \\
\text { deceleration [m/s2] }\end{array}$ \\
\hline Safe & 3,37 \\
Little Unsafe & 3,97 \\
Unsafe & 4,48 \\
Very Unsafe & 4,95 \\
\hline
\end{tabular}

\section{EXPERIMENT}

The measurements dealt with two spheres of investigation, first one focused on the change of speed and second one on the change of direction. The aim of the first experiment was to find the value of the vehicle's deceleration in the course of braking, where the participants of road traffic (drivers and passengers) began to feel subjectively rising danger (unsafety), or they considered this deceleration a sudden change of speed, respectively. In the second experiment, we were trying to find the values of side acceleration, which particular respondents assessed as dangerous, or considered this value of side acceleration a sudden change of direction.

\subsection{Measuring equipment}

The venue (location) for these driving tests was chosen first of all according to a sufficient area for conducting these tests safely. It was always a flat surface (Old Airport Service Area) without any significant defects and pot-holes as well as cross and longitudinal gradient. For measuring the individual driving maneuvers we used measuring apparatuses XL Me-

Table 2. Summary of used vehicles.

\begin{tabular}{|c|c|c|c|c|}
\hline Type & Model year & Tires & System ABS & $\begin{array}{c}\text { Maximal deceleration } \\
\text { aMAX }[\mathrm{m} / \mathrm{s} 2]\end{array}$ \\
\hline Mini John Cooper Works Cabrio & 2013 & Dunlop SP Sport 205/45 R17 & Yes & 10,1 \\
\hline Citroën Saxo 1,1 & 1998 & Barum Brillantis 165/70 R13 & No & 8,2 \\
\hline Daewoo Matiz 0,8 SE & 2002 & Fulda Multihawk 155/70 R13 & No & 8,5 \\
\hline Volkswagen Golf Plus V 1,4 MPI & 2008 & Michelin Primacy 205/55 R16 & Yes & 9,4 \\
\hline Škoda Octavia II 1,9 TDI & 2008 & Barum Polaris2 195/65 R15 & Yes & 8,8 \\
\hline
\end{tabular}


ter by Inventure and PicDAQ by DSD Linz. The data measured were consequently exported and processed in Excel software by Microsoft. The vehicles used for conducting the measurements are listed in Table 2. The fact that the vehicle had or had not the ABS influenced only driving manoeuvres of maximum deceleration. With vehicles without the ABS, the wheels got blocked earlier. Also, the maximum achieved deceleration was lower. The respondents' assessment did not reflect this fact (whether the vehicle had or had not the ABS).

\subsection{Sample description}

The measurements were conducted with volunteers as respondents (mainly family members, friends and colleagues of the author). Unfortunately, the group of respondents was not gender-balanced, it comprised 16 men and 6 women. The persons who participated in the measurements as respondents ranged between 18 and 64 years of age. Their driving experience measured by the by driving licence from 0 to 46 years and the amount of their "driven" kilometres ranged from 0 to $1000000 \mathrm{~km}$. During the tests, the respondents took seats of passengers, or they drove, respectively. Their position can be seen in Figure 1.

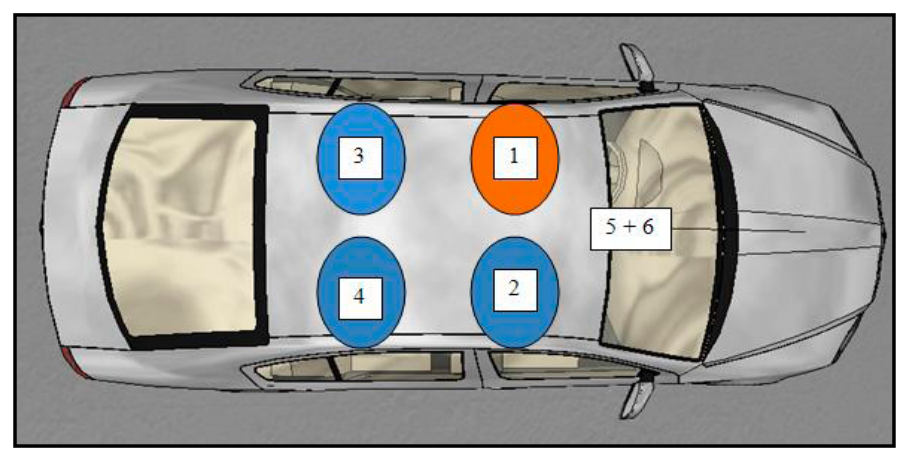

Figure 1. Deployment of crew and measuring equipment in the vehicle: 1 -driver, 2, 3 and 4-passenger, 5 a 6 measuring equipment.

\subsection{Driving manoeuvres}

For particular test drives we chose the starting speed of $50 \mathrm{~km} / \mathrm{h}$, which is the speed limit for driving in inhabited areas (if not altered by a local regulation), and is also a starting speed for evasive action's solutions in cases of not giving way at crossroads in the municipality area. For setting the starting speed in individual driving tests, we used a series speed indicator (or tempo master) mounted in the vehicle itself, or a GPS device. The value of speed indicator's error was verified by the GPS and by the apparatus for measuring the driving dynamics parameters. The vehicle with respondents always drove from zero speed to the starting speed. For a while, it drove at constant speed, followed by braking or avoidance manoeuvre. The point of the start of driving manoeuvre was at the moment of passing the gate marked with cones.

For measuring a sudden change of speed we chose the values of intensity of braking deceleration $3 \mathrm{~m} / \mathrm{s}^{2}, 5 \mathrm{~m} / \mathrm{s}^{2}, 7 \mathrm{~m} / \mathrm{s}^{2}$, and maximum attainable deceleration $a_{\max } \mathrm{m} / \mathrm{s}^{2}$. The choice of these values of deceleration was conditioned primarily by the aim of the experiment - to shift the limit of a sudden change of speed towards half the value of maximum adhesively attainable deceleration. Each driving test was conducted twice, so that we could settle most exactly the value of braking deceleration against the pre-given value.

When measuring a sudden change of direction of drive, we considered a driving manoeuvre - a transverse motion in one curve. The magnitude of the transverse motion was considered $3 \mathrm{~m}$ (as the equivalent of the width of one traffic lane). The speed of the vehicle in the process of the driving manoeuvre was $50 \mathrm{~km} / \mathrm{h}$. For individual driving manoeuvres we chose values of side acceleration $2 \mathrm{~m} / \mathrm{s}^{2}, 3 \mathrm{~m} / \mathrm{s}^{2}$, $4 \mathrm{~m} / \mathrm{s}^{2}$ and $6 \mathrm{~m} / \mathrm{s}^{2}$. The choice of these values of deceleration was oriented at the aim of the experiment: to find the most exact limit of a sudden change of direction of drive. Each test was conducted twice, so that we could settle most exactly the intended value of side acceleration. In order to enable the individual respondents to do the driving tests with the highest possible accord, they used a driving track demarcated by traffic cones, see Fig. 2. Driving tests were always conducted on a dry flat surface with good adhesive quality.

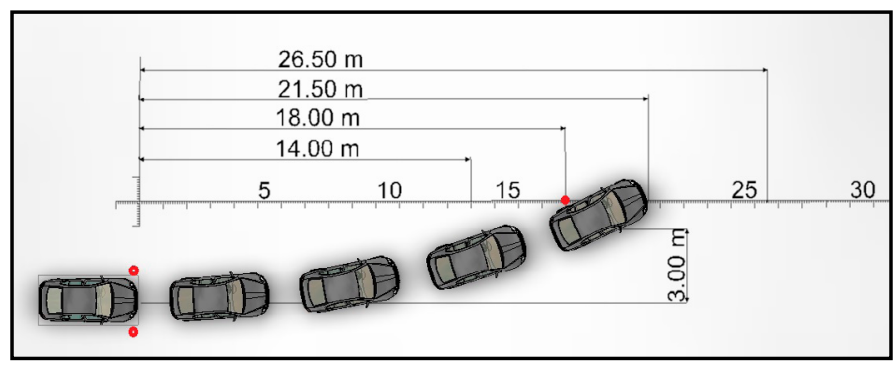

Figure 2. Trackway positions marked with cones (vehicle passes at a steady speed between the cones and then begins to move laterally to the left and the left side passes additional cone). 


\subsection{Measurement methods}

The respondents in the vehicle were tasked to assess subjectively during which of the realized maneuvers they felt achieving such a braking deceleration or side acceleration of the vehicle, which they found a starting danger, or a sudden change of speed or direction of drive. Before the driving tests, the respondents were instructed and briefly acknowledged with the given problematic. After each conducted test, the respondents' task was to define the degree of danger they felt at the maneuver, which they always marked in their questionnaire, (in which they also gave their age, gender, position in the vehicle, years of possession the driving licence, and driven kilometres total).

The criterion of classification was then their subjective feeling of starting danger. Four degrees of assessment were chosen:

- Safe

- Little unsafe

- Unsafe

- Very unsafe

Some of the conducted driving manoeuvres couldn't be included for big difference between real and estimated acceleration level, or because of a faulty measurement. For a sudden change of speed, we measured and assessed 120 values. For a sudden change of direction of drive, we measured and assessed 88 values. In Figure 3 we show records of driv- ing maneuvers for individual degrees of assessment of a sudden change of speed in the form of braking deceleration with various intensity. The axles of the measuring apparatuses were oriented in the way that plus values of acceleration represent the vehicle's acceleration and minus values its deceleration. The records of individual driving maneuvers for setting the limit of a sudden change of direction of drive are shown in Figure 4. Driving maneuvers were always conducted for yaw left, plus values of side acceleration show yaw left, minus values show yaw right. We always assessed only the first change of direction to the left, the following turning to the right only represented a correction back to the direction of drive of the vehicle.

\section{RESULTS}

When assessing the driving tests according to the individual degrees of assessment, we always extracted all values marked by the particular degree. Subsequently we calculated the frequency in \% for individual braking decelerations, and we made a conclusion.

\subsection{Sudden change of speed}

If we supposed that a sudden change is such one that doesn't evoke any danger, then the edge between a sudden state and a non-sudden one would

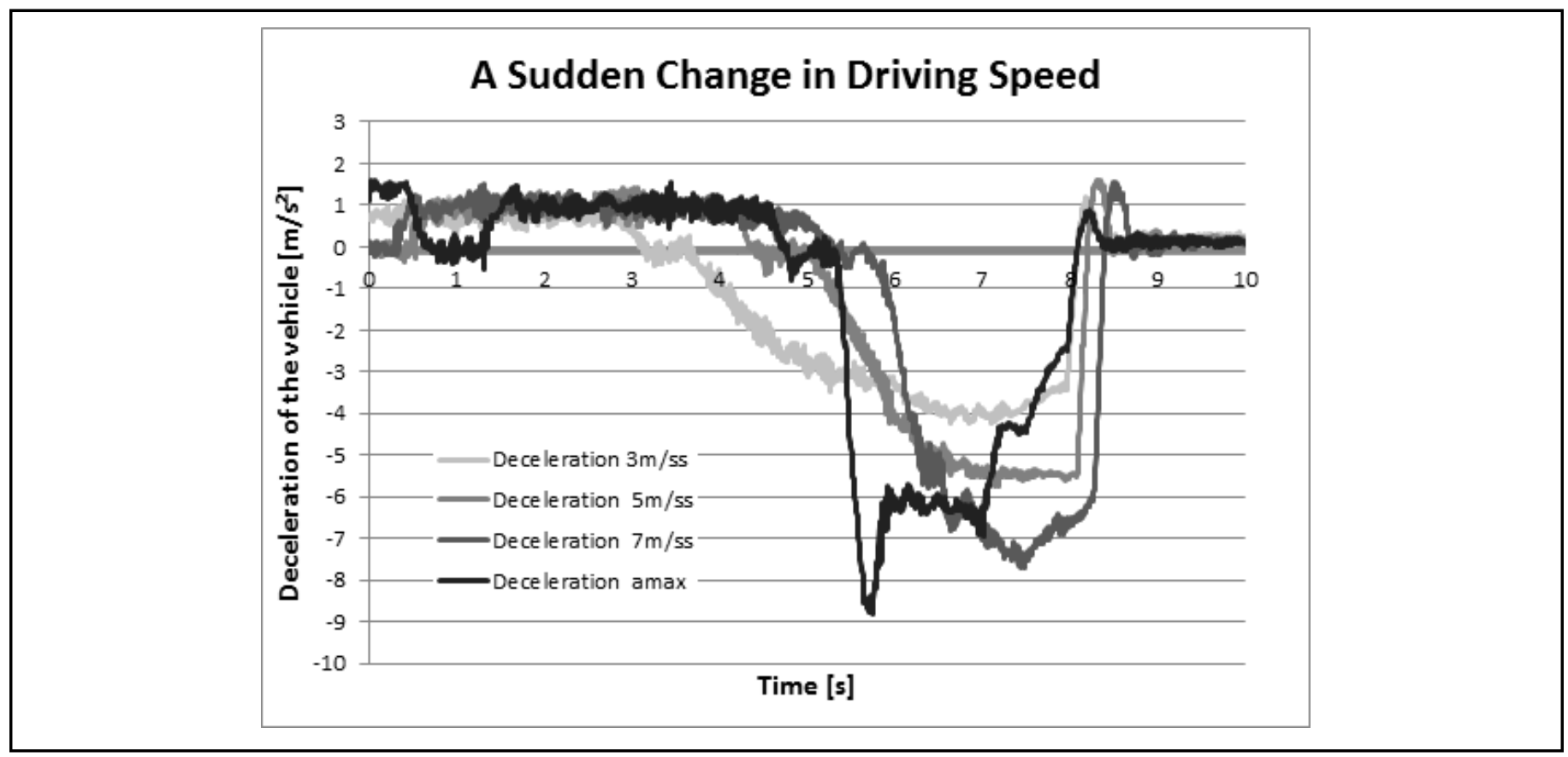

Figure 3. Records driving maneuvers - a sudden change in driving speed, vehicle VW Golf V Plus. 


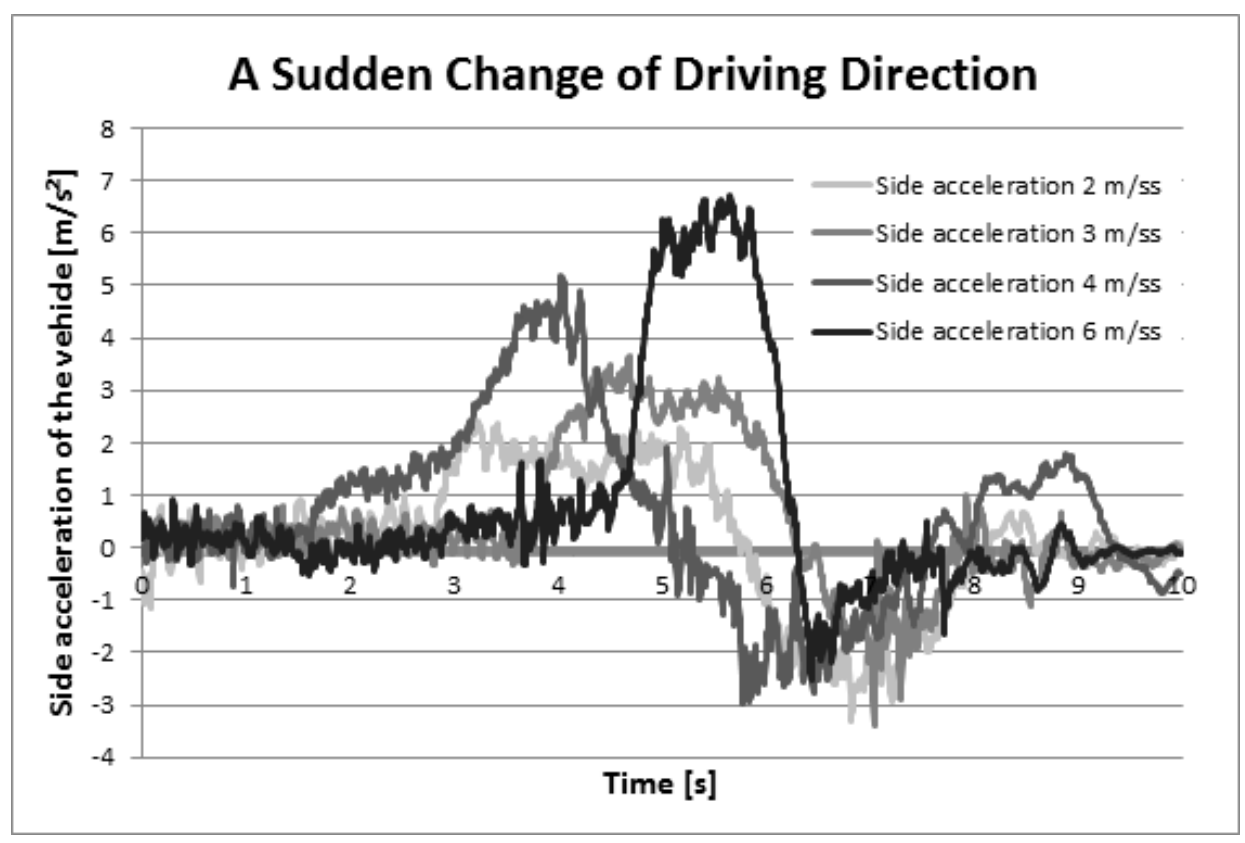

Figure 4. Records driving maneuvers - a sudden change of driving direction, vehicle VW Golf V Plus.

mean a value reflecting the category of assessment "safe". The edge value would oscillate within acceptable spectre towards the average of braking deceleration approximately $3,8 \mathrm{~m} / \mathrm{s}^{2}$ (expressed by simple arithmetic approximation of all values marked by particular degree of assessment). Many respondents understood the state "little unsafe" as lowering their comfort, not as starting danger. It's then recommendable to focus also on this group when searching the edge between a sudden change of speed or direction of drive, respectively. If we took into account the state "little unsafe", for which the approximate value of braking deceleration is approximately $5,9 \mathrm{~m} / \mathrm{s}^{2}$, we would get - according to the author of this thesis - more adequate value of the interval of a sudden change of speed.
When joining these two assessing groups, we will get an approximate value of braking deceleration $4,8 \mathrm{~m} / \mathrm{s}^{2}$, coming from assessment of 76 driving manoeuvres.

From the results achieved we can conclude, that the highest frequency of individual degrees of assessment responds the chosen braking decelerations in the same order. This feature proved the author's proper choice of values of individual braking decelerations.

The achieved results for individual degrees of assessment of "a sudden change of speed of drive" are in a box plot in Figure 5. The line amidst the box shows the median, the edges of the box are limits of 25 and 75 percentile, edge values represent 5 and 95 percentile of the given values.

Table 3. Summary evaluation of driving tests to determine the sudden change in driving speed.

\begin{tabular}{lllll}
\hline $\begin{array}{l}\text { Deceleration } \\
{\left[\mathrm{m} / \mathrm{s}^{2}\right]}\end{array}$ & $\begin{array}{l}\text { Relative frequency of } \\
\text { assessment "Safe" [\%] }\end{array}$ & $\begin{array}{l}\text { Relative frequency of } \\
\text { assessment “Little unsafe" [\%] }\end{array}$ & $\begin{array}{l}\text { Relative frequency of } \\
\text { assessment "Unsafe" [\%] }\end{array}$ & $\begin{array}{l}\text { Relative frequency of } \\
\text { assessment "Very unsafe" [\%] }\end{array}$ \\
\hline 3 & 70,8 & 2,9 & 0 & 0 \\
5 & 26,8 & 57,1 & 0 & 0 \\
7 & 2,4 & 34,2 & 61,5 & 100 \\
\hline
\end{tabular}






Figure 5. Dependence the degrees of assessment of the deceleration of the vehicle.

\subsection{Sudden change of direction}

For the category of assessment "safe" the value of side acceleration was in acceptable range towards approximate value of side acceleration approximately $2,7 \mathrm{~m} / \mathrm{s}^{2}$ (expressed by simple arithmetic approximation of all values marked by the particular degree of assessment). If we also considered state of "little unsafe" for which the approximate value of side acceleration is approximately $3,8 \mathrm{~m} / \mathrm{s}^{2}$, we would - according to the author - get a more adequate value of interval of sudden change of speed. By joining these two assessing groups we will get approximate value of side acceleration $3,1 \mathrm{~m} / \mathrm{s}^{2}$,coming from assessment of 63 driving maneuvers.
As well as at measuring driving manoeuvres for setting the limit for a sudden change speed, when measuring driving manoeuvres for setting the limit for a sudden change of direction, we can see, that the highest frequency of individual degrees of assessment responds to chosen side acceleration in the same order. But with the category of assessment "very unsafe" it is necessary to respect that only three values were assessed by this degree, which didn't project into the results of the measurement.

The achieved results for individual degrees of assessment of "a sudden change of driving direction" are in a box plot in Figure 6.

Figure 6. Dependence the degrees of assessment of the side acceleration of the vehicle.

Table 4. Summary evaluation of driving tests to determine the sudden change of driving direction.

\begin{tabular}{cccc}
\hline Side acceleration $\left[\mathrm{m} / \mathrm{s}^{2}\right]$ & $\begin{array}{c}\text { Relative frequency of } \\
\text { assessment "Safe" [\%] }\end{array}$ & $\begin{array}{c}\text { Relative frequency of assessment } \\
\text { "Little unsafe" [\%] }\end{array}$ & $\begin{array}{c}\text { Relative frequency of } \\
\text { assessment "Unsafe" [\%] }\end{array}$ \\
\hline 2 & 50 & 0 & 0 \\
3 & 44,7 & 64 & 0 \\
4 & 5,3 & 32 & 18 \\
6 & 0 & 4 & 82 \\
\hline Number of values & 38 & 25 & 22 \\
\hline
\end{tabular}




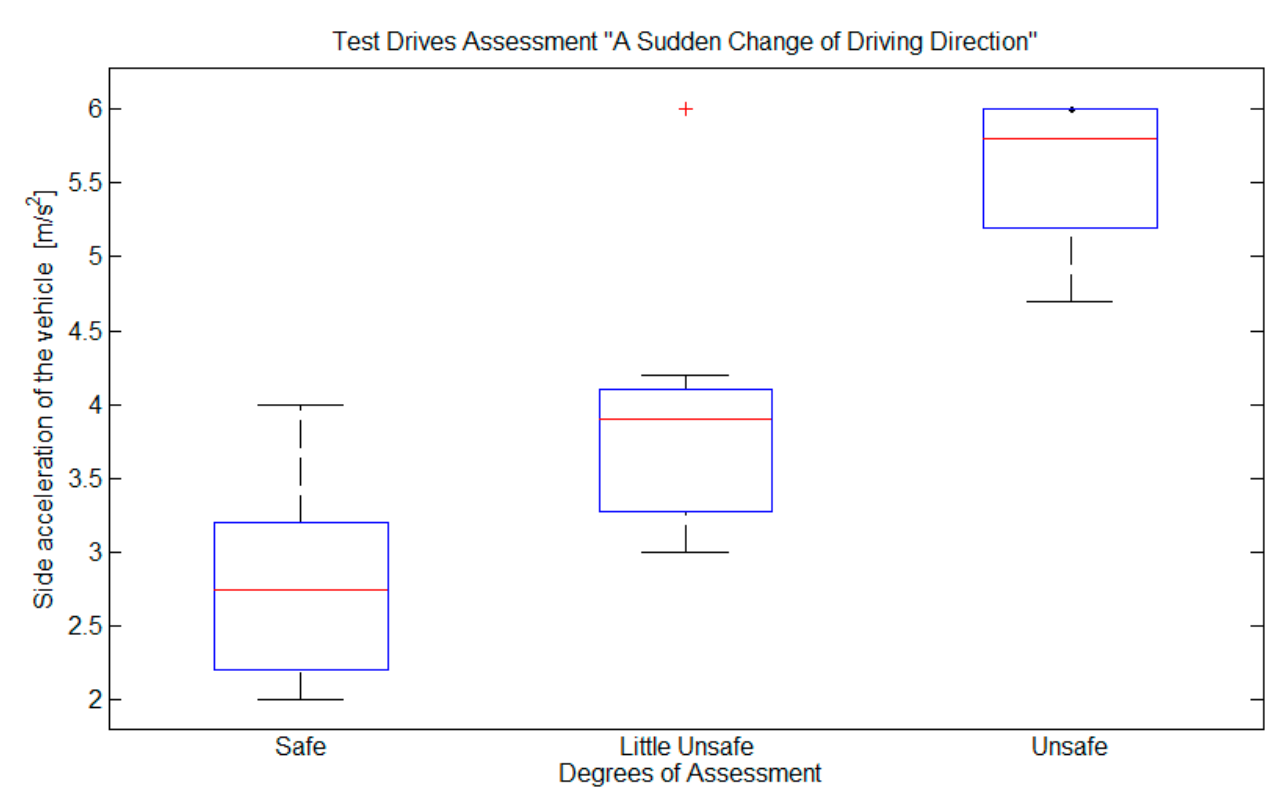

Figure 5. Dependence the degrees of assessment of the deceleration of the vehicle.

\section{DISCUSSION}

\subsection{Sudden change of speed}

To set an unambiguous edge value between a sudden and non-sudden change of speed is very difficult. This is caused first of all by the fact that individual respondents assessed subjectively the start of danger at various driving decelerations. Setting the edge "sudden $x$ non-sudden" can be considered from more assessment criteria, if we came from the premise that non-sudden change of speed is such one that would be assessed only by degree "unsafe", then the approximate value of such braking deceleration would be $3,8 \mathrm{~m} / \mathrm{s}^{2}$. If we considered for setting the value of sudden change of speed the joint degree of "safe + little unsafe", the approximate value of so assessed braking deceleration would be $4,8 \mathrm{~m} / \mathrm{s}^{2}$. For definite setting the edge value of a sudden change of speed, it is better to give the interval of values. If we come from the above derived approximate values of braking deceleration, we will get the value between non-sudden and sudden change of speed ranging from 3,8 to $4,8 \mathrm{~m} / \mathrm{s}^{2}$, expressed by braking deceleration.

When comparing the results of conducted measurements with the results mentioned in literature Langle and Dantu (2009), it is obvious that the derived value between non-sudden and sudden change of speed, then between the state of safe and unsafe ranged from 3,8 and $4,8 \mathrm{~m} / \mathrm{s}^{2}$ and matches the published results, when authors Langle and
Dantu considered safe deceleration up to $3 \mathrm{~m} / \mathrm{s}^{2}$, and unsafe deceleration was around $6 \mathrm{~m} / \mathrm{s}^{2}$. So the results of the conducted measurements exact the edge between the state of safe and the state of unsafe.

The author further dealt with assessing according to particular specific criteria, which were: driving experience of the respondents, their sex, and also their position in the vehicle during the driving tests. From the classified results it didn't come out explicitly that driving experience doesn't influence subjective perception of danger, as it was declared in literature Lukášik (2010). This fact was confirmed only with drivers with the highest amount of driven kilometres. If we focus on the influence of the sex of respondents on perception of danger, there was no significant difference between men and women, so they were in accord. Comparing the edge value between non-sudden and sudden change of speed ranging from 3,8 to $4,8 \mathrm{~m} / \mathrm{s}^{2}$ with the criterion value between non-sudden and sudden change of speed from literature Lukášik (2010) ranging from 3,7 to $4,0 \mathrm{~m} / \mathrm{s}^{2}$, we can deduce obvious shift towards higher values of braking deceleration reaching values of $1 / 2 \mathrm{a}_{\max }$, it means half the maximum attainable deceleration on given conditions. This shift may be due to certain differences in the measurements, first of all in the chosen values for particular assessed braking decelerations, or conditions of individual driving tests (it means the vehicle, the weather, the exterior, etc.). 
Table 5. Assessment "Safe" according to gender, position in the vehicle and driving experience.

\begin{tabular}{lccccc}
\hline Deceleration $\left[\mathrm{m} / \mathrm{s}^{2}\right]$ & 3 & 5 & 7 & Number of values & Average value of deceleration $\left[\mathrm{m} / \mathrm{s}^{2}\right]$ \\
\hline Male & $75 \%$ & $21,9 \%$ & $3,1 \%$ & 32 & 3,8 \\
Female & $66,7 \%$ & $33,3 \%$ & 0 & 9 & 3,8 \\
\hline Driver & $60 \%$ & $30 \%$ & $10 \%$ & 10 & 4,1 \\
Co-driver & $100 \%$ & 0 & 0 & 7 & 3,3 \\
Left at the back & $78 \%$ & $22 \%$ & 0 & 9 & 3,6 \\
Right at the back & $60 \%$ & $40 \%$ & 0 & 15 & 4 \\
\hline $0-50.000 \mathrm{Km}$ & $66,7 \%$ & $33,3 \%$ & 0 & 12 & 3,8 \\
$50.001-150.000 \mathrm{Km}$ & $70,5 \%$ & $23,5 \%$ & $6 \%$ & 17 & 3,4 \\
$150.001-500.000 \mathrm{Km}$ & $85,7 \%$ & $14,3 \%$ & 0 & 7 & 4 \\
$500.001-1.000 .000 \mathrm{Km}$ & $60 \%$ & $40 \%$ & 0 & 5 & \\
\hline
\end{tabular}

\subsection{Sudden change of direction}

For starting parameters set for our experiment starting speed $50 \mathrm{~km} / \mathrm{h}$, transverse motion approximately $3 \mathrm{~m}$ and values of side acceleration 2,3 , 4, and $6 \mathrm{~m} / \mathrm{s}^{2}$ we can sort out limits of sudden $\mathrm{x}$ non-sudden change of direction in the same way, it means according to complex assessment of the degree "safe + little unsafe", when we made use of 63 values. Arithmetic approximation of the values of so assessed side acceleration resulted in $3,1 \mathrm{~m} / \mathrm{s}^{2}$. For final setting the limit value it is more adequate to mention the interval of values. If we come from the above derived approximate value of side acceleration, we will get the value between sudden and non-sudden change of direction ranging from $2,7 \mathrm{~m} / \mathrm{s}^{2}$ to $3,5 \mathrm{~m} / \mathrm{s}^{2}$, expressed by side acceleration of the vehicle.

Results of the measurements done by the author for setting the limit of sudden change of direction ranging from 2,7 to $3,5 \mathrm{~m} / \mathrm{s}^{2}$ are in the middle of the values published in Langle and Dantu (2009), where they considered the changes of traffic lanes. Then, it was probably a transverse motion through two curves by transverse distance of 3,7 m. Authors Langle and Dantu set the value of a safe of traffic lanes for driving manoeuvres with the value of side acceleration up to $2 \mathrm{~m} / \mathrm{s}^{2}$. An unsafe change of traffic lanes was expressed by driving manoeuvres with the value of side acceleration ranging from 4 to $5 \mathrm{~m} / \mathrm{s}^{2}$. The value set in this the-

Table 6. Assessment "Safe" according to gender, position in the vehicle and driving experience.

\begin{tabular}{lccccc}
\hline Side acceleration $\left[\mathrm{m} / \mathrm{s}^{2}\right]$ & 2 & 3 & 4 & Number of values & Average value of side acceleration $\left[\mathrm{m} / \mathrm{s}^{2}\right]$ \\
\hline Male & $57,6 \%$ & $38,5 \%$ & $3,8 \%$ & 26 & 2,7 \\
Female & $50 \%$ & $41,7 \%$ & $8,3 \%$ & 12 & 2,7 \\
\hline Driver & $43,2 \%$ & $42,6 \%$ & $14,2 \%$ & 13 & 2,9 \\
Co-driver & $55,6 \%$ & $44,4 \%$ & 0 & 9 & 2,6 \\
Left at the back & $71,4 \%$ & $28,6 \%$ & 0 & 7 & 2,5 \\
Right at the back & $44,4 \%$ & $55,6 \%$ & 0 & 9 & 2,8 \\
\hline $0-50.000 \mathrm{Km}$ & $41,9 \%$ & $49,8 \%$ & $8,3 \%$ & 12 & 2,9 \\
$50.001-150.000 \mathrm{Km}$ & $56,2 \%$ & $37,5 \%$ & $6,3 \%$ & 16 & 2,6 \\
$150.001-500.000 \mathrm{Km}$ & $50 \%$ & $50 \%$ & 0 & 8 & 2,7 \\
$500.001-1.000 .000 \mathrm{Km}$ & $50 \%$ & $50 \%$ & 0 & 2 & 2,9 \\
\hline
\end{tabular}


sis finds itself almost amidst these values and so it can be considered a correct one. A higher value of side acceleration at unsafe change of traffic lanes might have been caused by the vehicle used. The values presented in Bradáč Jr. (2005) are almost in accord with Langle and Dantu (2009), where for a usual drive the considered values of side acceleration are approximately $2 \mathrm{~m} / \mathrm{s}^{2}$. In comparison with the assessment of avoidance manoeuvres in thesis Kledus (2003) the limit of sudden and non-sudden change of direction responds the degree of assessment 'fluent drive' with dynamic impression on the crew in the range of values of side acceleration from 2,5 to $3,8 \mathrm{~m} / \mathrm{s}^{2}$. This value is almost in accord with the derived value of non-sudden and sudden change of direction. For comparison, it can also be stated that driving manoeuvres assessed as unsafe, with approximate side acceleration $5,5 \mathrm{~m} / \mathrm{s}^{2}$ were classified in thesis Kledus (2003) as dynamic (sports) drive, ranging from 5,2 to $6,4 \mathrm{~m} / \mathrm{s}^{2}$. Here we can see a different setting of assessment scale driving manoeuvres in each thesis.

\section{CONCLUSION}

Setting the value of a sudden change of speed can also be recognized as a change of state between a safe and already unsafe driving manoeuvre. From the results of the measurements we get the value between nonsudden and sudden change of speed of the vehicle ranging from 3,8 to $4,8 \mathrm{~m} / \mathrm{s}^{2}$, expressed by braking deceleration of the vehicle. This result of all realized measurements is nearly in accord with hypothesis that if the limit of a sudden change of speed was absolutely safe (non-sudden), the change of speed mustn't be realized with deceleration bigger than $1 / 2 a_{\max }$, it means half the maximum attainable deceleration of the vehicle on given conditions. From many realized braking tests of personal vehicles (primarily for the sake of forensic practice) we can derive maximum braking deceleration ranging from 8 to $10 \mathrm{~m} / \mathrm{s}^{2}$, at most modern vehicles even above $10 \mathrm{~m} / \mathrm{s}^{2}$. Then, $1 / 2 a_{\max }$ with personal vehicles can be considered in the range between approximately 4 to $5 \mathrm{~m} / \mathrm{s}^{2}$.

For assessing a sudden $\mathrm{x}$ non-sudden change of direction, as the assessment parameter we used the side acceleration of the vehicle in the course of the given driving manoeuvre, which the respondents as the crew of the vehicle had to classify subjectively in the relation to possible rising danger. For setting the limit value between a sudden $\mathrm{x}$ non-sudden change of direction, we can come from the above derived approximate value of side acceleration, then we get the value for a non-sudden and sudden change of direction ranging from 2,7 to $3,5 \mathrm{~m} / \mathrm{s}^{2}$, expressed by the side acceleration of the vehicle.

The results of the experiment cannot be compared with TTC results. In this experiment, respondents rated the maneuver, respectively how the deceleration and side acceleration felt to them.

The assessed limit values can be used in forensic practice especially in calculative modeling the participants' behavior, in technical solutions of traffic accidents. First of all in relation to all the duties that come from formulations used in legal regulations of the rules of road traffic.

It should also be declared that all measurements were realized on merely ideal conditions: dry surface (good adhesive conditions) and a sufficiently large testing venue. In real traffic situations, we would also have to respect the length of reaction time of individual drivers, because it would have a significant deal in subjective assessment of particular situations. That is why it would be useful to make another set of measurements at different speeds for verifying attained results, or to specify the methodology so that it would also respect individual drivers' reaction time. In the end, it is necessary to stress that all measurements were conducted with personal vehicles. If lorries or trucks were used, we could expect different results.

Acknowledgements: My thanks go to my family, my colleagues and friends, who all took an active part in the conducted measurements as respondents, or helped realize them. I would also like to thank the Institute of Forensic Engineering, Brno University of Technology for support with realization of the measurements themselves.

\section{REFERENCES}

Bradáč, A. a kol. (1999) Soudní inženýrství. Brno: CERM. ISBN 80-720-4133-9.

Burg, H., Moser, A. (2009) Handbuch Verkehrsunfallrekonstruktion: Unfallaufnahme, Fahrdynamik, Simulation. 2. aktualisierte Aufl. Wiesbaden: Vieweg Teubner, ISBN 978-38348-0546-1.

Rivers, R. (2010) Technical traffic crash investigators' handbook a technical reference, training, investigation and reconstruction manual. 3rd ed. Springfield: Charles C. Thomas Publisher. ISBN 978-0-398-07907-9. 
Langle, L., Dantu R. (2009) Are you a Safe Driver. In Proceedings of the International Conference on Computational Science and Engineering. p. 502-507. ISBN 978-0-7695-3823.

Park, K.S., Lee, A.J., and Koh, B.K. (2001) Drivers' Characteristics in the Perception of a Lead Vehicle's Deceleration Level. International Journal of Cognitive Ergonomics, Vol. 5, Num. 2, p. $125-136$.

Vogel, K. (2003) A comparison of headway and time to collision as safety indicators. Accident Analysis and Prevention, Vol. 35, p. 427-433.

Kusano, K. D., Gabler. H. C. (2011) Methodfor Estimating Time to Collision at Braking in Real-World, Lead Vehicle Stopped Rear-End Crashes for Use in Pre-Crash System Design. SAE Technical Paper, 2011-01-0576, 2011, doi: 10.4271/2011-01-0576.

Kusano, K. D., Chen, R., Montgomery, J. and Gabler. H. C. (2015) Population distributions of time to collision at brake application during car following from naturalistic driving data. Journal of Safety Research, Vol. 54, p. 95-104.

Kledus, R. (2003) Modelování pohybu vozidla prri analýze silničních nehod - vyhýbací manévr. (Unpublished doctoral dissertation). Brno University of technology, Czech Republic.

Bradáč A. Jr. (2005) Př́čné premístění vozidel při analýze silniční nehody. . (Unpublished doctoral dissertation). Brno University of technology, Czech Republic.

Lukášik, M. (2010) Vybrané specifika technického výkladu pravidel cestnej premávky při technickej analýze dopravných nehod. (Unpublished doctoral dissertation). University of Žilina, Slovak Republic.

Besip (2016) Zákon č. 361/2000 Sb., o provozu na pozemních komunikacích. Retrieved from http://www.ibesip.cz/cz/legislativa/silnicni-zakon-s-komentarem 